Jurnal Pendidikan Dasar PerKhasa

Volume 4, Nomor 2, Oktober 2018

\title{
EFEKTIVITAS PROJECT BASED LEARNING (PJbL) BERBASIS TRANSFER NILAI-NILAI PANCASILA DALAM MENINGKATKAN KETERAMPILAN MENULIS BUKU AJAR PKn SD BAGI MAHASISWA PGSD UMC
}

\author{
Dianasari, Hanikah, Diana Setiana \\ Universitas Muhammadiyah, Cirebon, Indonesia \\ email: ceritadiana@yahoo.com, hanikah@umc.ac.id, diana.setiana@umc.ac.id
}

\begin{abstract}
The purpose of this study was to improve the writing skills of UMC PGSD students in grade 5 primary school on a Civics textbooks through the project based learning model (PjBL) based on the transfer of Pancasila values. This study uses an experimental method (Single-One Group Pretest-Posttest Design) with instruments: assessment sheets, portfolios, observation sheets, and questionnaire sheets. The research subjects were students who were prospective elementary school teachers who contracted the fourth semester Civics Learning subjects at the PGSD Study Program. The study sample consisted of 40 students from the SD16-A4 class. Effectiveness was analyzed using n-gain and T test. The results of the research were in the 5th grade Civics Civics printed textbook based on the transfer of Pancasila values and the improvement of the writing skills of elementary school textbooks for students. The acquisition of n-gain value for each indicator of writing skills in Civics teaching books is: content eligibility of 0.70 (high), language feasibility of 0.63 (moderate), presentation eligibility of 0.57 (moderate) and graphic feasibility of 0,57 (medium). The magnitude of the correlation value $(R)$ is 0.815 and the results of the $R$ Square or determinant coefficient (R2) are 0.663 or 66.3 which means the influence of the PjBL model based on the transfer of Pancasila values to the writing skills of Civics textbooks is $66.3 \%$. The 33.7 is influenced by other factors outside the PjBL model (excluding $x$ variables). The conclusion that can be drawn is, PjBL learning based on transfer of Pancasila values can be said to be quite effective in improving the textbook writing skills of UMC PGSD students.
\end{abstract}

Keywords: Project Based Learning, Civics Textbooks, Transfer of Pancasila values.

Abstrak: Tujuan penelitian ini adalah meningkatkan keterampilan menulis mahasiswa PGSD UMC dalam membuat bukuajar PKn SD kelas 5 melalui modelpembelajaran proyek atau Poject Based Learning (PjBL) berbasis transfer nilai-nilai Pancasila. Penelitian ini menggunakan metode eksperimen (Single-One Group Pretest-Posttest Design) dengan instrument: lembar penilaian, portofolio, lembar observasi, dan lembar angket. Subjek penelitian yaitu mahasiswa calon guru SD yang mengontrak mata kuliah Pembelajaran PKn semester IV di Prodi PGSD.Sampel penelitian berjumlah 40 mahasiswa dari kelas SD16-A4. Efektivitas dianalisis menggunakan n-gain dan uji T...Hasil penelitian berupa buku ajar cetak PKn SD kelas 5 berbasis transfer nilai-nilai Pancasila danpeningkatan keterampilan menulis buku ajar SD pada mahasiswa.Perolehan nilai n-gain pada setiap indikator keterampilan menulis buku ajar PKn adalah: kelayakan isi sebesar0,70 (tinggi), kelayakan bahasa sebesar 0,63 (sedang), kelayakan penyajian sebesar 0,57 (sedang) dan kelayakan kegrafikan 
Jurnal Pendidikan Dasar PerKhasa, Volume 4, Nomor 2, Oktober 2018

sebesar 0,57 (sedang). Besarnya nilai korelasi $(R)$ sebesar 0,815 dan dijelaskan hasil $R$ Square atau koefisien determinan (R2) sebesar 0,663 atau 66,3 yang artinya pengaruh model PjBLberbasis transfer nilai-nilai Pancasila terhadap keterampilan menulis buku ajar PKn sebesar 66,3\%. Adapun 33,7 dipengaruhi oleh faktor lain diluar dari model PjBL (diluar variabel $\mathrm{x}$ ). Kesimpulan yang dapat ditarik adalah, pembelajaran PjBL berbasis trasfer nilainilai Pancasila dapat dikatakan cukup efektif dalam meningkatkan keterampilan menulis buku ajar Pkn mahasiswa PGSD UMC.

Kata Kunci: Project Based Learning,Buku ajar PKn, Transfer nilai-nilai Pancasila.

Pendahuluan

Mata kuliah Pendidikan Kewarganegaraan (PKn) wajib dikontrak oleh mahasiswa S1 PGSD FKIP Universitas Muhammadiyah Cirebon (UMC). Sebagai salah satu mata kuliah bidang studi, Pembelajaran PKn di Sekolah Dasar (SD) bertujuan untuk memberikan keterampilan, kemampuan dasar mengajar dan pemahaman mahasiswa dalam menerapkan metode dan strategi pembelajaran $\mathrm{PKn}$ di Sekolah Dasar yang didasari prinsipprinsip pembelajaran yang mendidik dan bermuatan nilai, norma, moral serta pendidikan karakter berikut kegiatan evaluasi hasil belajarnya.Mata kuliah ini dirasa tepat sebagai mata kuliah yang di dalamnya diintegrasikan materi-materi ajar berbasis nilai-nilai Pancasila.

Tetapi yang terjadi selama ini mata kuliah pendidikan kewarganegaran di berbagai perguruan tinggi di Indonesia hanya bersifat hapalan tidak lebih hanya seperti "transfer of knowledge" saja, tidak ada nilai-nilai dan pelajaran yang bisa diambil dan dirasakan ketika mengikuti perkuliahan, dan jarang sekali mata kuliah Pendidikan Kewarganegaraan dijadikan sebagai mata kuliah "role model" untuk permasalahanpermasalahan bangsa dan negara, seperti permasalahan pendidikan.Dengan tujuan utama untuk meningkatkan keterampilan menulis buku ajar bagi mahasiswa. Buku ajar PKn yang dibuat mahasiswa diharapkan dapat meningkatkan pengetahuan dan kompetensi menulis, kemudian kegiatan latihan menulis buku ajar akan berpengaruh terhadap keterampilan menulis mahasiswa untuk menjadi lebih terampil, berpengalaman serta berkarakter. 
Efektivitas Project Based Learning (Pjbl) Berbasis Transfer Nilai-Nilai...

Capraro, et al., (2013: 52) mengatakan, pembelajaran Berbasis Proyek lebih cocok untuk pengajaran interdisipliner karena secara alami melibatkan banyak keterampilan akademik yang berbeda, seperti membaca, menulis, dan matematika serta cocok untuk membangun pemahaman konseptual melalui asimilasi mata pelajaran yang

berbeda.SementaraThomas,

Mergendoller, and Michaelson(1999) menulis,proyek adalah tugas yang kompleks berdasarkan tema yang menantang, yang melibatkan siswa dalam mendesain, memecahkan masalah, mengambil keputusan, atau kegiatan investigasi; memberikan kesempatan kepada siswa untuk bekerja dalam periode waktu yang telah dijadwalkan dalam menghasilkan produk.

Hanafiah dan Suhana (2009: 30) mengatakan, model pembelajaran ini merupakan model pembelajaran inovatif yang melibatkan kerja proyek dimana peserta didik bekerja secara mandiri dalam mengkonstruksi pembelajarannya dan mengkulminasikannya dalam produk nyata.Menurut NYCDepartement of
Education (2009:8), model pembelajaran $\mathrm{PjBL}$ merupakan strategi pembelajaran dimana siswa harus membangun pengetahuan konten mereka sendiri dan mendemonstrasikan pemahaman baru melalui berbagai bentuk representasi.Melalui PjBL diharapkan keterampilan menulis buku ajar calon guru Sekolah Dasar akan lebih baik sehingga kualitas pembelajaran yang didapatkan sesuai dengan tujuan pendidikan nasional.

Bahan ajar menurut Prastowo (2013) merupakan segala bahan (baik informasi, alat maupun teks) yang disusun secara sistematis, yang menampilkan sosok utuh dari kompetensi yang akan dikuasai peserta didik dan digunakan dalam proses pembelajaran dengan tujuan perencanaan dan penelaahan implementasi pembelajaran, misalnya buku pelajaran, modul, handout, LKS, model atau maket, bahan ajar audio, bahan ajar interaktif dan sebagainya.Pemanfaatan bahan ajar dalam proses pembelajaran memiliki peran penting. Peran tersebut menurut Belawati, dkk. (2003: 1.4-1.9) meliputi peran bagi guru, siswa, dalam 
Jurnal Pendidikan Dasar PerKhasa, Volume 4, Nomor 2, Oktober 2018

pembelajaran klasikal, individual, maupun kelompok.

Buku ajar PKn yang disusun mahasiswa diarahkan untuk pendalaman materi PKn terhadap nilai-nilai Pancasila. Jadi dalam penjelasan setiap materi PKn berdasarkan tema yang ada di kelas $\mathrm{V}$ SD. Sehingga guru bisa memberikan contoh perilaku yang menjiwai Pancasila, dan menghasilkan siswa yang berjiwa Pancasilais.Atas dasar permasalahan tersebut maka dilakukan penelitian Efektivitas Project Based Learning (PjBL) Berbasis Transfer Nilai-Nilai Pancasila dalam Meningkatkan Keterampilan Menulis Buku Ajar PKn SD Bagi Mahasiswa PGSD UMC.

\section{Metode}

Penelitian ini menggunakan metode penelitian kuantitatif-deskriptif. Dalam Nazir (2005: 54) dikatakan, metode kuantitatif digunakan untuk melakukan pengukuran-pengukuran, sedangkan metode deskriptif bertujuan untuk membuat deskripsi, gambaran atau lukisan secara sistematis, faktual dan akurat mengenai faktafakta, sifat-sifat serta hubungan antarfenomena yang diselidiki. Dengan demikian, metode kuantitatif-deskriptif ini digunakan untuk mengukur dan mendeskripsikan dengan jelas dan rinci mengenai peningkatan keterampilan menulis bahan ajar bagi mahasiswa PGSD.

Penelitian ini dilakukan selama 3 bulan dari bulan Maret-Mei 2018.Subjek dalam penelitian ini adalah mahasiswa PGSD semester 4 PGSD UMC. Jumlah Mahasiswa semester 4 pada tahun ajaran 2017/2018 berjumlah 205, dari jumlah tersebut yang diambil sebagai sampel penelitian berjumlah 40 orang yaitu satu kelas yang memiliki jumlah mahasiswa terbanyak yaitu Kelas SD16-A4.

Variabel yang diteliti yaitu PjBL sebagai variabel bebas (variable independent), dan keterampilan menulis bahan ajar PKn berbasis transfer nilainilai pancasila sebagai variabel terikat (variable dependent). Instrumen yang digunakan dalam penelitian ini adalah lembar portofolio dan lembar observasi.Selanjutnya data yang diperoleh dalam penelitian ini diolah dan dianalisis menggunakan teknik statistik deskriptif, meliputi rata-rata, standar deviasi, nilai maksimum dan nilai 
Efektivitas Project Based Learning (Pjbl) Berbasis Transfer Nilai-Nilai...

minimum. Penilaian keterampilan mahasiswa calon guru SD dalam menyusun bahan ajar PKn SD Kelas 5 berbasis transfer nilai-nilai Pancasila berdasarkan berbagai kriteria yaitu komponen kelayakan isi, komponen kelayakan kebahasaan, Komponen kelayakan penyajian dan komponen kegrafikan.
Selanjutnya data keterampilan menulis calon guru SD dikategorikan secara kuantitatif berdasarkan teknik kategorisasi.Kemudian hasil skor pengolahan nilai keterampilan menulis calon guru SD tersebut, dikriteriakan dengan kriteria penilaian seperti Tabel 1.

Tabel 1. Kriteria Penilaian Keterampilan Menulis BukuAjar Mahasiswa Calon Guru

\begin{tabular}{rll}
\hline No & Rentang Skor & Kriteria \\
\hline 1 & $3,01<$ skor $\leq 4,00$ & Terampil \\
2 & $2,01<$ skor $\leq 3,00$ & Cukup Terampil \\
3 & $1,01<$ skor $\leq 2,00$ & Kurang terampil \\
4 & $0<$ skor $\leq 1,00$ & Tidak terampil \\
\hline
\end{tabular}

Selanjutnya data tersebut dianalisis untuk mengetahui peningkatan keterampilan menulis mahasiswa calon guru SD dalam menyusun bukuajar PKn berbasis transfer nilai-nilai Pancasila menggunakan gain ternormalisasi. Kriteria keberhasilan berdasarkan uji $\mathrm{n}$ gain dapat ditentukan dengan indikator seperti Tabel 2.

\begin{tabular}{|c|c|}
\hline$\langle g\rangle$ & Kriteria \\
\hline $0,7 \leq \mathrm{g}$ & Tinggi \\
\hline $0,3 \leq \mathrm{g}<0,7$ & Sedang \\
\hline$g<0,3$ & Rendah \\
\hline
\end{tabular}

Selain itu, dalam kegiatan pengolahan data ini digunakan T-Test (one sample ttest) yang dilakukan untuk mengetahui perbedaan mean variabel yang dihipotesiskan dan mengetahui tingkat efektivitas dari pembelajaran $\mathrm{PjBL}$ terhadap keterampilan menulis buku ajar PKn SD Kelas 5 oleh mahasiswa PGSD. 


\section{Hasil dan Pembahasan}

\section{A. Pretes sebelum melaksanakan PjBL}

Pelaksanaan pretes dilakukan pada awal perkuliahan semester genap sebelum implementasi PjBL yaitu pada hari Rabu tanggal 14 Maret 2018 dan Rabu tanggal 21 Maret 2018. Dari pertemuan ini, mahasiswa belum memahami konsep bahan ajar yang sesungguhnya. Dari hasil pretes didapat nilai rata-rata indikator pada kelayakan isi adalah 2,74 nilai rata-rata indikator pada kelayakan bahasa adalah 2,86 dan rata-rata indikator pada kelayakan penyajian adalah 2,35 rata-rata indikator pada kelayakan kegrafikan adalah 2,99. Dengan demikian rata-rata skor keterampilan menulis bahan ajar berada pada skor 2,74 (cukup terampil). Lebih jelasnya lihat Gambar 1.

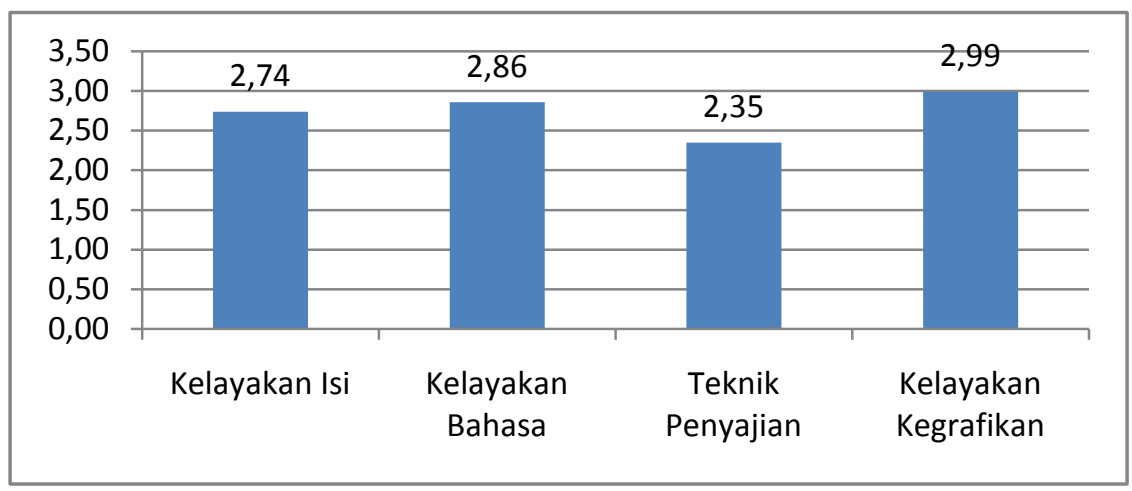

\section{Gambar 1. Nilai Rata-rata Pretes}

Setelah mengetahui nilai pretes setiap indikator langkah selanjutnya adalah menjumlahkan nilai pada setiap indikator dan didapat nilai akhir pretes.
Nilai akhir pretes dianalisis menggunakan microsoft excel 2010. Adapun analisis hasil dapat dilihat pada Tabel 3.

Tabel 3. Hasil Analisis Data Pretes Keterampilan Menulis Bahan Ajar

\section{Statistik Nilai Statistik Pretes}

\begin{tabular}{lc}
\hline Sampel & 40 \\
Nilai Minimum & 2,00 \\
Nilai Maximum & 3,25 \\
Nilai Rata-rata & 2,73 \\
Standar Deviasi & 2,33 \\
\hline
\end{tabular}


Efektivitas Project Based Learning (Pjbl) Berbasis Transfer Nilai-Nilai...

\section{B. Pelaksanaan PjBL}

Setelah melakukan pretes, langkah kedua adalah melaksanakan treatmen dengan menggunakan PjBL sebanyak 3 kali pada hari Rabu tanggal 4 April 2018, tanggal 11 April 2018, dan Senin 23 April 2018. Treatmen ini dilaksanakan sesuai dengan langkah-langkah pembelajaran PjBL.

1. Merancang Tujuan (Design Purpose) yaitu mendefinisikan masalah

Pelaksanaan implementasi: Pada tahapan ini, mahasiswa melakukan kegiatan diskusi yang berkaitan dengan masalah-masalah pembelajaran di SD. Masalahmasalah tersebut diantaranya pembelajaran yang disajikan kurang efektif dan interaktif. Selain itu, tujuan pembelajaran lebih sulit dicapai oleh siswa terutama pada pembelajaran PKn. Pada langkah ini juga, mahasiswa membatasi permasalahan pembelajaran yang bersumber pada buku ajar.

2. Mengajukan pertanyaan/inquiry (Field Inquiry) yaitu mendefinisikan aspek inquiri dalam cakupan
Pelaksanaan

implementasi:

Langkah ini dilakukan oleh mahasiswa dengan menganalisis masalah buku ajar PKn. Berbagai masalah yang berkaitan dianalisis penyebabnya apakah bersumber dari siswa, guru, atau pemerintah. Pada tahapan ini juga, mahasiswa mendapatkan sejumlah pertanyaan yang berkaitan dengan rendahnya kemampuan guru dalam menyusun buku ajar sehingga menyebabkan pembelajaran di kelas kurang efektif.

3. Mengajukan alternatif pemecahan masalah (solution alternative) yaitu melibatkan pertimbangan alternatif pemecahan masalah terhadap masalah yang dirumuskan

Pelaksanaan implementasi:

Tahapan yang dilakukan oleh mahasiswa pada langkah ini yaitu dengan beberapa alternatif pemecahan masalah yang harus diselesaikan. Mahasiswa sebagai calon guru mendiskusikan pengertian buku ajar dan menganalisis berbagai cara untuk dapat menyusun buku ajar diantaranya dengan menganalisis 
model-model pengembangan bahan ajar yaitu model "ASSURE" dan "ADDIE". Berdasarkan model-model tersebut, mahasiswa mengkaji alternatif yang paling memudahkannya dalam menyusun buku ajar secara sederhana.

4. Memilih solusi yang tepat (Choosing the Preffered Solution) : memilih salah satu solusi alternatif yang tepat

Pelaksanaan

implementasi:

Berdasarkan langkah sebelumnya, langkah ini dilakukan oleh mahasiswa dengan memilih model "ASSURE" sebagai langkah untuk menyusun bahan ajar PKn sesuai dengan kurikulum dan kebutuhan siswa. Adapun materi PKn yang disusun berdasarkan kurikulum 2013 yaitu kurikulum terbaru yang menggunakan tema dalam setiap pembelajaran. Selain itu, sebagai bahan latihan menulis, mahasiswa calon guru menentukan tema "Berbagai Pekerjaan" yang ada pada kelas 4 semester 1 untuk dibuat buku ajar sehingga memudahkan mahasiswa dalam menyusun bahan ajar yang kontekstual dan sesuai dengan kebutuhan siswa di SD.

5. Tahap Pelaksanaan (Operation Step): Merencanakan metode untuk implementasi solusi yang dipilih.

Pelaksanaan implementasi: Pada tahapan ini, mahasiswa calon guru dibuat 5 kelompok besar sesuai dengan subtema yang ada pada mata pelajaran PKn kelas 5 SD.

6. Evaluasi (Evaluation): mengevaluasi keseluruhan proses dan produk yang dihasilkan.

Pelaksanaan implementasi: Langkah ini dilakukan dengan mengevaluasi hasil buku ajar yang telah dibuat oleh mahasiswa calon guru.

\section{Hasil posttest penerapan PjBL}

Pelaksanaan post tes dilakukan setelah implementasi PjBL yaitu pada hari Rabu tanggal 2 Mei 2018 dan Rabu tanggal 9 Mei 2018. Dari pertemuan ini, mahasiswa telah memahami konsep bahan ajar yang sesungguhnya. Lebih jelasnya lihat Gambar 2. 
Efektivitas Project Based Learning (Pjbl) Berbasis Transfer Nilai-Nilai...

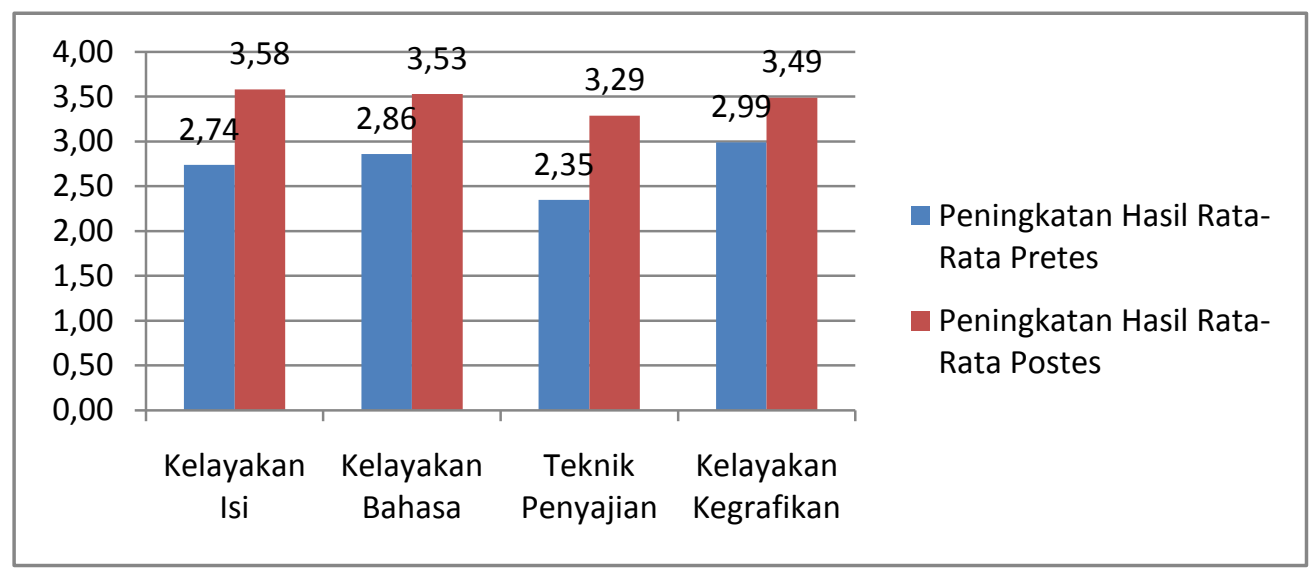

Gambar 2. Peningkatan Hasil Rata-rata Pretes dan Postes

Pada kategori kelayakan isi, mahasiswa calon guru mendapatkan nilai 3,58 dengan kategori terampil karena cakupan materi, akurasi materi, mengandung kecakapan hidupmengandung wawasan kebinekaan dan mengandung wawasan konstektual. Bahan ajar yang dibuat dalam postes ini sudah relevan dengan kebutuhan dan karakteristik siswa SD. Materi yang disusun sudah mempunyai nilai kontekstual materi ajar. Kategori kelayakan bahasa, mendapat skor 3,53 dengan kategori terampil. Hal ini disebabkan pada aspek ini, mahasiswa sudah menghasilkan bahan ajarkesesuaian dengan perkembangan peserta didik komunikatif, dialog dan interaktif, lugas. Namun belum menunjukkan adanya koherensi dan keruntutan alur berpikir,kesesuaian dengan kaidah bahasa indonesia, penggunaan istilah dan simbol/lambang yang konsisten.Kemudian pada kategori kelayakan penyajian, skor yang didapat adalah 3,29 masuk dalam kategori terampil, namun kategori ini cenderung jauh lebih rendah dari aspek lainnya. Hal ini disebabkan masih ada mahasiswa yang bahan ajar dibuat masih ada sedikit ketidak konsistenan dalam penyajian pembelajaran dan rendahnya nilai pendukung penyajian.Pada katagori komponen kegrafikan, skor yang 
Jurnal Pendidikan Dasar PerKhasa, Volume 4, Nomor 2, Oktober 2018

didapat adalah 3,49. Hal ini disebabkan ukuran/format,desain bagian kulit, kualitas kertas, desain bagian isi sudah maksimal.

Tabel 4. Hasil N-Gain setiap Indikator Keterampilan Menulis Bahan Ajar

\begin{tabular}{ccc} 
Indikator Keterampilan Menulis & Hasil N-Gain & Kriteria \\
\hline Kelayakan Isi & 0.70 & Tinggi \\
Kelayakan Bahasa & 0.63 & Sedang \\
Teknik Penyajian & 0.57 & Sedang \\
Kelayakan Kegrafikan & 0.57 & Sedang \\
\hline
\end{tabular}

Berdasarkan Tabel 4 maka

(sedang), pada kelayakan penyajian dapat disimpulkan bahwa nilai $\mathrm{n}$-gain dari setiap indikator keterampilan adalah 0,57 (sedang) dan pada menulis buku ajar PKn adalah nilai kelayakan kegrafikan 0,57 (sedang).

Adapun hasil pengolahan data pada kelayakan isi 0,70 (tinggi), pada kelayakan bahasa adalah 0,63 dengan menggunakan SPSS 20 dapat dilihat pada Tabel 5.

Tabel 5.Model summary

\begin{tabular}{|l|c|r|r|r|}
\hline Model & $\mathrm{R}$ & $\mathrm{R}$ Square & Adjusted R Square & $\begin{array}{c}\text { Std. Error of the } \\
\text { Estimate }\end{array}$ \\
\hline 1 &, $815^{\mathrm{a}}$ &, 663 &, 655 &, 06155 \\
\hline
\end{tabular}

a. Predictors: (Constant), PjBL

b. Dependent Variable: Keterampilan

Berdasarkan Tabel 5 (Model Summary) menjelaskan besarnya nilai korelasi/hubungan $(R)$ yaitu sebesar 0,815 dan dijelaskan hasil $R$ Square atau koefisien determinan (R2) sebesar 0,663 atau 66,3 yang artinya bahwa pengaruh model $\mathrm{PjBI}$ terhadap keterampilan menulis buku ajar PKn sebesar $\quad 66,3 \%$. Adapun 33,7 dipengaruhi oleh faktor lain diluar dari model PjBL (diluar variabel $\mathrm{x}$ ). Setelah didapat hasil model summary, kemudian output kedua didapat hasil Anova. Hasil Anova ini untuk menjelaskan apakah ada pengaruh yang nyata (signifikan) variabel PjBL $(x)$ terhadap variabel 
Efektivitas Project Based Learning (Pjbl) Berbasis Transfer Nilai-Nilai...

keterampilan menulis bahan ajar. Hasilnya dapat dilihat pada Tabel 6 .

Tabel 6. ANOVA

\begin{tabular}{|c|c|c|c|c|c|}
\hline Model & $\begin{array}{c}\text { Sum of } \\
\text { Squares }\end{array}$ & $\overline{d f}$ & $\begin{array}{l}\text { Mean } \\
\text { Square }\end{array}$ & $\bar{F}$ & Sig. \\
\hline Regression & ,284 & 1 & ,284 & 74,923 &, $000^{b}$ \\
\hline 1 Residual & 144 & 38 & ,004 & & \\
\hline Total & ,428 & 39 & & & \\
\hline
\end{tabular}

a. Dependent Variable: Keterampilan

b. Predictors: (Constant), PjBL

Berdasarkan Tabel 6 terlihat bahwa Fhitung $=74,923$ dengan tingkat signifikan/probabilitas $\quad 0,000 \quad 0,05$ maka model regresi dapat dipakai untuk memprediksi variabel keterampilan menulis bahan ajar calon guru. Maka hasil dari perhutungan regresi dengan menggunakan SPSS 20, terdapat output ketiga yaitu coefficients. Oleh karena itu agar lebih jelas maka dapat dilihat pada Tabel 7.

Tabel 7.Coefficients ${ }^{a}$

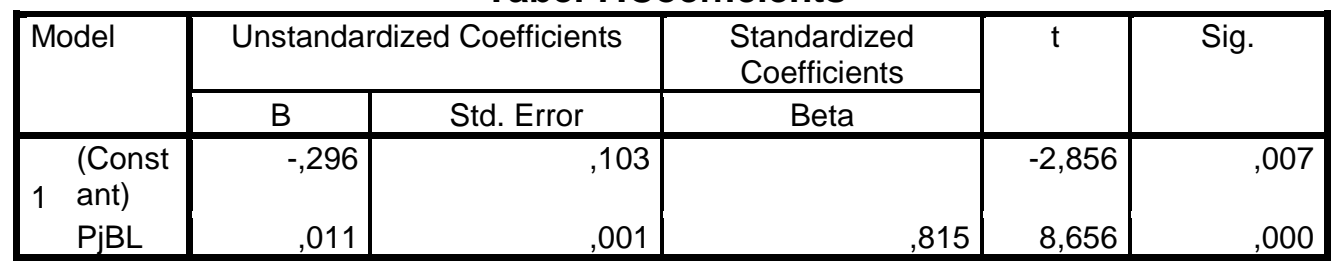

a. Dependent Variable: Keterampilan

Berdasarkan Tabel 7 di atas, terdapat kolom B pada Constan (a) adalah 0,296 sedangkan nilai PjBL (b) adalah 0,11 sehingga persamaan regresinya dapat ditulis $Y=a+b X$ atau 0,296 + 0,11X. Dari persamaan tersebut dapat diterjemahkan bahwa konstanta sebesar 0,296 menyatakan bahwa jika tidak ada nilai PjBL maka nilai keterampilan menulis buku ajar PKn sebesar 0,296. Kemudian jika koefisien regresi $X$ sebesar 0,11 menyatakan bahwa setiap penambahan 1 nilai PjBL, maka nilai keterampilan menulis buku ajar PKn bertambah sebesar 0,11. 
Hasil penilaian efektivitas PjBL berbasis transfer nilai-nilai Pancasila yang dilakukan pada saat pretes dan posttes mengarah kepada peningkatan keterampilan menulis bahan ajar PKn calon guru SD. Hasilnya dapat dilihat pada

Tabel

8.

Tabel 8. Hasil penilaian efektivitas PjBL dalam Menulis Bahan Ajar PKn

\begin{tabular}{lccc}
\hline \multicolumn{1}{c}{ Indikator } & Pretes & Postes & n-gain \\
\hline Kelayakan Isi & 2.74 & 3.58 & 0.70 \\
Kelayakan Bahasa & 2.86 & 3.53 & 0.63 \\
Teknik Penyajian & 2.35 & 3.29 & 0.57 \\
Kelayakan Kegrafikan & 2.99 & 3.49 & 0.57 \\
\hline
\end{tabular}

Berdasarkan Tabel 8., dapat disimpulkan bahwa setiap indikator keterampilan menulis buku ajar yaitu kelayakan isi, kelayakan bahasa, kelayakan penyajian,serta kelayakan kegrafikan terdapat peningkatan dilihat dari nilai gain yang diperoleh. Pada masing-masing indikator mengalami peningkatan rata-rata skor yang diperoleh oleh mahasiswa. Analisis skor posttes dar masing-masing indikator: kelayakan isi 3,58 ada pada kategori terampil, kelayakan bahasa 3,53 ada pada kategori terampil, teknik penyajian 3,29 ada pada kategori terampil, dan kelayakan kegrafikan 3,49 ada pada kategori terampil. Sehingga dapat disimpulkan bahwa pembelajaran berbasis proyek atau
PjBL berbasis transfer nilai-nilai Pancasila efektif meningkatkan keteramppilan menulis bahan ajar PKn SD bagi mahasiswa PGSD UMC.

Pada Tabel 7., selain menggambarkan persamaan regresi, dapat dilihat juga uji signifikansi dengan uji t yaitu untuk mengetahui apakah ada pengaruh nyata antara variabel $\mathrm{PjBL}(\mathrm{X})$ terhadap variabel keterampilan menulis buku ajar PKn. Adapun hasil hipotesis dari hasil tersebut adalah:

1. Jika \pm thitung $< \pm$ ttabel, maka $\mathrm{H} 0$ diterima dan $\mathrm{H} 1$ ditolak.

2. Jika \pm thitung $> \pm$ ttabel, maka $\mathrm{HO}$ ditolak dan $\mathrm{H} 1$ diterima.

HO: tidak ada pengaruh yang nyata (signifikan) variabel model PjBL (X) 
Efektivitas Project Based Learning (Pjbl) Berbasis Transfer Nilai-Nilai...

terhadap variabel Keterampilan Menulis Buku Ajar PKn

$\mathrm{H} 1$ : ada pengaruh yang nyata (signifikan) variabel model PjBL $(X)$ terhadap variabel Keterampilan Menulis Buku Ajar PKn.

Nilai $t_{\text {hitung }}=8,656$ dan $t_{\text {tabel }}$ dicari dengan tabel distribusi t pada taraf kepercayaan 95\% ( $\alpha=5 \%$, karena uji $\mathrm{t}$ bersifat dua sisi, maka nilai $\alpha / 2=5 \% / 2$ $=0,025)$ dan derajat bebas $(\mathrm{df})=\mathrm{n}-2=$ $40-2=38$, sehingga $t(0,025 ; 38)=$ 2,024. Karena t hitung sebesar 8,656 lebih besar dari (`) 2,024, sehingga dapat disimpulkan bahwa maka HO ditolak dan $\mathrm{H} 1$ diterima yang berarti bahwa ada pengaruh yang nyata (signifikan) variabel $X$ yaitu model $\mathrm{PjBL}$ terhadap variabel $Y$ yaitu keterampilan menulis bahan ajar PKn.

\section{Simpulan dan Saran}

Berdasarkan hasil analisis data menunjukkan model pembelajaran berbasis proyek atau Project Based Learning ( $\mathrm{PjBL}$ ) membantu mahasiswa dalam meningkatkan pengetahuan dan keterampilan yang kokoh dan bermakna- guna (meaningful-use) yang dibangun melalui tugas-tugas dan pekerjaan yang otentik.Pembelajaran yang baik adalah pembelajaran yang dapat meningkatkan kompetensi peserta didik agar makin berkembang dengan mengooptimalkan potensi yang ada dalam diri mereka. Tujuan utama inilah yang akan merangsang setiap pendidik untuk mempu berinovasi dalam kegiatan pembelajaran yang baik. Termasuk dalam mata kuliah Pendidikan Kewarganegaraan yang dirasa cukup monoton menjadi menarik karena adanya sentuhan pembelajaran yang modern berbasis proyek namun tetap mengedepankan nilai-nilai moral Pancasila sebagai acuan utama.

\section{Daftar Pustaka}

Abbas, S. 2006. Pembelajaran Bahasa Indonesia yang Efektif di Sekolah Dasar. Jakarta: Departemen Pendidikan Nasional.

Belawati, T., dkk. (2003). Pengembangan Bahan Ajar. Jakarta: Pusat Penerbitan UT.

Capraro, et al. 2013. STEM ProjectBased Learning : An Integrated Science, Technology, Engineering, and Mathematics (STEM) Approach 
Jurnal Pendidikan Dasar PerKhasa, Volume 4, Nomor 2, Oktober 2018

(second ed). Rotterdam : Sense Publishers.

Panen, P., dan Purwanto. (2004). Penulisan Bahan Ajar. Jakarta: Ditjen Dikti Depdikbud.

Daryanto. 2009. Panduan Proses Pembelajaran Kreatif \& Inovatif. Jakarta: Publisher.

Doppelt, Y. 2005. Assessment of Project Based Learning in a Mechatronicts Context.Journal of Technology Education. Volume 16, number 2.

Hanafiah, N. dan Suhana,C. 2009. Konsep Strategi Pembelajaran. Bandung: Refika Aditama.

Hasan, A. 2007. Kamus Besar Bahasa Indonesia. Jakarta: Balai Pustaka.

Nazir, M. 2005. Metode Penelitian. Jakarta: Ghalia Indonesia.

NYC Departement of Education (2009). Project Based Learning: Inspiring Middle School Student to Engage in Deep and Active Learning. New York : Division of Teaching and Learning Office.

Prastowo, A. (2013). Pengembangan Bahan Ajar Tematik: Panduan Lengkap Aplikatif. Jogjakarta: Diva Press.

Proet, J. \& Gill, K. (1986). The Writing Process in Action: A Handbook for Teachers. Urbana: NCTE.

Sani, A. dan Ridwan.2014. Pembelajaran Saintifik untuk Implementasi Kurikulum 2013.Jakarta: Bumi Aksara.

Tarigan, H. G. 2008. Menulis Sebagai Suatu Keterampilan Berbahasa. Bandung: Angkasa.

Thomas, J.W., Margendoller, J.R., \& Michaelson, A. 1999. Project-Based Learning: A. Handbook for Middle and High School Teachers. http://www.bgsu.edu/organizations/c tl/proj.html.

Pengakuan: Penelitian ini didukung penuh oleh Kementerian Riset dan Teknologi Direktorat Pendidikan Tinggi, pada tahun anggaran 2018 dalam skema Penelitian Dosen Pemula. 